\title{
TENNIS ELBOW - CRITICAL ANALYSIS OF VARIOUS CONSERVATIVE TREATMENT MODALITIES
}

\author{
Kanniyappan Thanigaimani1 ${ }^{1}$ Chinnaiyan Rajkumar ${ }^{2}$
}

${ }^{1}$ Associate Professor, Department of Orthopaedics, Government Chengalpet Medical College, Chengalpet, Tamilnadu. ${ }^{2}$ Assistant Professor, Department of Orthopaedics, Government Chengalpet Medical College, Chengalpet, Tamilnadu.

\section{ABSTRACT}

\section{AIM}

The purpose of this study was to evaluate the outcome of various conservative treatment modalities used in tennis elbow.

\section{METHODS}

Five commonly used conservative modalities were tested in fifty tennis elbow patients, i.e. 1. Ultrasonic therapy, 2 . Inj. Methylprednisolone, 3. Inj. 50\% Dextrose, 4. Inj. Autologous blood, 5. Inj. Platelet rich plasma. They were all periodically followed for one year. The final outcome was analysed with visual analogue pain score.

\section{RESULTS}

With ultrasonic therapy out of ten patients, six patients (60\%) had improved from symptoms. Four patients did not get relief or improvement of symptoms even after four complete sittings of ultrasonic therapy. With injection Methylprednisolone, $70 \%$ patients had improved from symptoms; $30 \%$ of patients did not get relief; $80 \%$ of patients who received $50 \%$ dextrose injections had improved from symptoms and $20 \%$ of patients did not get relief of symptoms. Following autologous blood injections $90 \%$ of patients had improved from symptoms, but recurrences were noted. Following platelet rich plasma treatment, $90 \%$ of patients had improved from symptoms.

\section{CONCLUSIONS}

Platelet rich plasma injection seems to be the best method of conservative treatment for tennis elbow.

\section{KEYWORDS}

Tennis Elbow, Conservative Modalities, Ultrasonic Therapy, Methylprednisolone, Platelet Rich Plasma.

HOW TO CITE THIS ARTICLE: Thanigaimani K, Rajkumar C. Tennis elbow - critical analysis of various conservative treatment modalities. J. Evolution Med. Dent. Sci. 2016;5(67):4801-4804, DOI: 10.14260/jemds/2016/1094

\section{INTRODUCTION}

Tennis elbow is defined by lateral elbow pain on palpation of the common extensor origin and pain on resisted wrist extension. It is generally considered to be due to repetitive microtrauma from the overuse of wrist extensors and subsequent failure of the tendon to heal and the most common muscle found to be affected is Extensor Carpi Radialis Brevis, which is a part of Common Extensor Origin from lateral epicondyle. Tennis elbow is the most commonly diagnosed elbow condition. ${ }^{1}$

The prevalence of tennis elbow is $1-2 \%$, and the condition is mainly seen among middle-aged people and females.-4 Although, it has a well-defined clinical presentation and there is an abundance of research on tennis elbow, the complexities of both the underlying aetiological and pathophysiological processes remain in contention. Specifically, whether an inflammation is an integral part of the pathogenesis.

Many of therapeutic interventions are available for the treatment of tennis elbow, of the comparatively a few randomised control trials which have been undertaken, no one proven treatment to be universally effective. ${ }^{5}$

Financial or Other, Competing Interest: None.

Submission 01-07-2016, Peer Review 26-07-2016,

Acceptance 01-08-2016, Published 22-08-2016.

Corresponding Author:

Kanniyappan Thanigaimani,

\#S8, Leo Block, V.G.N.

Zodiac Ville, 62, Devadoss Street,

V.G.N. Avenue, Phase 1, Mogappair West,

Chennai-37.

E-mail: orthomani2002@gmail.com

DOI: $10.14260 /$ jemds/2016/1094
Hence, this study was carried out to assess the results of different conservative modalities of management.

\section{Study Subjects}

Our study involved 50 patients with Tennis Elbow, treated conservatively in the Department of Orthopaedics from $1^{\text {st }}$ January 2015 to December 2015 at Chengalpet Medical College, Chengalpet, Tamilnadu.

\section{Study Type}

This is a prospective descriptive study.

\section{METHODOLOGY}

Approval from the Hospital Ethical Committee was taken. Informed and written consent was taken from the patient. The conservative management given at the Outpatient Department. Then the patient followed in the Outpatient Department at weekly intervals till symptoms decreases and then followed up for 3 weeks, 6 weeks, 3 months, 6 months and 12 months interval depends on the compliance of the patient by visual analogue scale.

\section{Criteria for Inclusion}

- Pain on palpation of the common extensor origin on the lateral epicondyle.

- $\quad$ Pain elicited from the common extensor origin during resisted extension of the wrist.

- $\quad$ Age more than 18 years.

\section{Exclusion Criteria}

- Arthritis.

- Synovitis of proximal radio-ulnar joint. 
- Entrapment of radial nerve and posterior interosseous nerve.

- Generalised pain syndrome.

- Previous history of trauma or surgery in the region of the lateral epicondyle and common extensor origin.

- Other diseases like medial epicondylitis, impaired sensibility, paralysis, etc., that would affect the outcome measure.

- Those patients who lost for follow-up were also excluded from our study.

The Criteria for Diagnosing Tennis Elbow as Suggested by Garden $^{6}$ in 1961 and followed in this Study were as follows

1. Local tenderness at the lateral epicondylar region.

2. Pain in the same region on resisted radial extension of the wrist.

3. Pain in the same region on the passive stretching of the forearm extensors.

\section{Methods of Treatment}

- Ultrasonic Therapy.

- Injection of Methylprednisolone (Depo-Medrol).

- Injection of $50 \%$ Dextrose.

- Injection of Autologous Blood.

- Injection of Platelet Rich Plasma.

Dosage of 50\% Dextrose: Sterile aqueous suspension of $2 \mathrm{cc}$ of $50 \%$ dextrose has been used. Depending on the effect of cure, the injections were repeated but not less than 15 days. Patients who have not shown any improvement by 4 injections were deemed as failures.

Dosage of Methylprednisolone: For all cases, sterile aqueous suspension of $1 \mathrm{~mL}$ of methylprednisolone containing $40 \mathrm{mg}$ per $\mathrm{mL}$ has been used. Depending on the effect of cure, the injections were repeated but not less than 15 days. Patients who have not shown any improvement by 4 injections were deemed as failures.

No special predilection for a method of treatment in a particular case was preferred and so the case selection was random except patient with diabetes, methylprednisolone and $50 \%$ dextrose are not used.

\section{Outcome Measurements and Follow-Up}

Patient followed up by visual analogue scale for pain intensity at 3 weeks, 6 weeks, 3 months, 6 months and 12 months by Visual Analogue Scale and results are assessed by patient's pain improved or not and recurrence of pain after treatment.

\section{OBSERVATIONS}

50 cases of Tennis Elbow have the basis of this study.

\section{Age and Sex Distribution}

The youngest patient in this series was a 19 years old boy and the oldest were a male and female aged 62 years. Majority of the patients were seen in the age group of 30 to 39 years (38\%). The average age incidence was 30 years.

\begin{tabular}{|c|c|c|c|c|}
\hline $\begin{array}{l}\text { Age Groups } \\
\text { in Years }\end{array}$ & $\begin{array}{c}\text { No. of } \\
\text { Patients }\end{array}$ & (\%) & Male & Female \\
\hline 10 yrs.- 19 yrs. & 1 & 2 & 1 & 0 \\
\hline 20 yrs. -29 yrs. & 13 & 26 & 8 & 5 \\
\hline 30 yrs. -39 yrs. & 19 & 38 & 6 & 13 \\
\hline 40 yrs. -49 yrs. & 10 & 20 & 3 & 7 \\
\hline 50 yrs. -59 yrs. & 6 & 12 & 2 & 4 \\
\hline 60 yrs. -69 yrs. & 1 & 2 & 0 & 1 \\
\hline Total & 50 & 100 & $\begin{array}{c}20 \\
(40 \%)\end{array}$ & $\begin{array}{c}30 \\
(60 \%)\end{array}$ \\
\hline \multicolumn{5}{|c|}{ Table 1: Age and Sex Distribution } \\
\hline
\end{tabular}

\section{Distribution of Treatment}

In this study, there are 5 groups of patients taken with five different methods of treatment and patients are chosen randomly and each group distributed evenly. In patients with diabetic mellitus treatment of $50 \%$ dextrose and methylprednisolone were not given.

\begin{tabular}{|c|c|c|}
\hline Treatment & No. of Patients & $(\%)$ \\
\hline Ultrasonic therapy & 10 & 20 \\
\hline Methylprednisolone & 10 & 20 \\
\hline $50 \%$ Dextrose & 10 & 20 \\
\hline Autologous blood & 10 & 20 \\
\hline Platelet rich plasma & 10 & 20 \\
\hline Total & 50 & 100 \\
\hline \multicolumn{3}{|c|}{ Table 2: Different Methods of Treatment } \\
\hline
\end{tabular}

\section{Distribution of Results}

In this series, results of treatment are formulated according to visual analogue scale which consists of 0 to 10 with 0 representing no pain, 10 representing worst possible pain and 5 is moderate pain. Improvement of symptoms assessed by decreasing score in the pain scale during every review of the patients.

\section{Results of Ultrasonic Therapy}

In this study, total of 10 patients (20\%) treated by ultrasonic therapy. Maximum of 4 sittings given. Out of 10 patients 6 patients $(60 \%)$ had improved from symptoms and 4 patients (40\%) did not get relieved or improved from symptoms even after 4 complete sittings of ultrasonic therapy. In first sitting, 4 patients $(40 \%)$ were improved from symptoms. In $2^{\text {nd }}$ and $3^{\text {rd }}$ sittings, 1 patient (10\%) each were improved from symptoms.

\section{Results of Injection Methylprednisolone}

In this study, a total of 10 patients (20\%) treated by injection methylprednisolone. Maximum of 4 injections given. Out of 10 patients, 7 patients $(70 \%)$ had improved from symptoms and 3 patients (30\%) did not get relieved or improved of symptoms even after 4 complete methylprednisolone injection.

In first injection, 4 patients $(40 \%)$ were improved from symptoms. In $2^{\text {nd }}, 3^{\text {rd }}$ and $4^{\text {th }}$ injections one patient $(10 \%)$ each were improved from symptoms.

\section{Results of $50 \%$ Dextrose}

In this study, a total of 10 patients (20\%) treated by $50 \%$ dextrose. Maximum of 4 injections given. Out of 10 patients, 8 patients (80\%) had improved from symptoms and 2 patients (20\%) did not get relieved or improved of symptoms even after 
4 complete injections of $50 \%$ dextrose. In first injection, 2 patients (20\%) were improved from symptoms.

In $2^{\text {nd }}$ injection 3 patients $(30 \%)$ were improved from symptoms, $3^{\text {rd }}$ injection 2 patients (20\%) were improved from symptoms and $4^{\text {th }}$ injection 1 patient improved from symptoms.

\section{Results of Autologous Blood}

In this study, a total of 10 patients (20\%) were treated by autologous blood injection. Maximum of 4 injections given. Out of 10 patients, 9 patients (90\%) had improved from symptoms and 1 patient $(10 \%)$ did not get relieved or improved of symptoms even after 4 complete injections of autologous blood. In first injection, 2 patients $(20 \%)$ were improved from symptoms. In $2^{\text {nd }}$ injection 4 patients $(40 \%)$ were improved from symptoms, $3^{\text {rd }}$ injection 2 patients $(20 \%)$ were improved from symptoms and $4^{\text {th }}$ injection 1 patient improved from symptoms.

\section{Results of Platelet Rich Plasma Injection}

In this study, a total of 10 patients (20\%) treated by injection Platelet Rich Plasma. Maximum of 4 injections were given. Out of 10 patients, 9 patients (90\%) had improved from symptoms and 1 patient $(10 \%)$ did not get relieved or improved of symptoms even after 4 complete injections of Platelet Rich Plasma. In first injection 5 patients (50\%) were improved from symptoms. In $2^{\text {nd }}$ injection 3 patients $(30 \%)$ were improved from symptoms, $3^{\text {rd }}$ injection 1 patient $(20 \%)$ was improved from symptoms.

\section{DISCUSSION}

\section{Ultrasonic Therapy}

\begin{tabular}{|c|c|c|}
\hline $\begin{array}{c}\text { Name of the } \\
\text { Author }\end{array}$ & $\begin{array}{c}\text { Results } \\
\text { (\%) }\end{array}$ & $\begin{array}{c}\text { Recurrence } \\
\text { (\%) }\end{array}$ \\
\hline Hohl (1961) & 58 & 52.21 \\
\hline Haake M (2002) & 54.6 & 48.34 \\
\hline A. P. Dvaz (2005) & 64 & 55.06 \\
\hline $\begin{array}{c}\text { Present study } \\
\text { (2015) }\end{array}$ & 60 & 53.84 \\
\hline \multicolumn{2}{|c|}{ Table 3: Incidence of Ultrasonic Therapy } \\
\hline
\end{tabular}

The effectiveness of ultrasonic therapy in the treatment of tennis elbow is viewed with doubt. There are only a few reports with statistical data published regarding the result of ultrasonic therapy in tennis elbow.

Qualitative study of ultrasonics are compared with this present study.

According to Coste et al in 1951 and Aldes in 1956, 51.4\% of patients improved of symptoms and recurrence of $56.92 \%$. According to Hohl (1961), 58\% of patients improved of symptoms and recurrence of $52.21 \%$. At present study $60 \%$ of the patients relieved of symptoms and recurrence of 53.84\%. Results of at present study are comparable with the other studies, which is conducted above.7,8 So the treatment of Tennis Elbow with ultrasonic therapy has low effect and high rate of recurrence.
Injection Methylprednisolone

\begin{tabular}{|l|c|c|}
\hline \multicolumn{1}{|c|}{$\begin{array}{c}\text { Name of the } \\
\text { Author }\end{array}$} & $\begin{array}{c}\text { Results } \\
\text { (\%) }\end{array}$ & $\begin{array}{c}\text { Recurrence } \\
\text { (\%) }\end{array}$ \\
\hline Smidt N et al (2004) & 68.03 & 45.18 \\
\hline Kutay E (2010) & 72.28 & 57.12 \\
\hline $\begin{array}{l}\text { Muhammad Saqib } \\
(2013)\end{array}$ & 65.42 & 50.71 \\
\hline $\begin{array}{l}\text { Present study } \\
(2015)\end{array}$ & 70 & 42.86 \\
\hline \multicolumn{2}{|c|}{ Table 4: Incidence of Methylprednisolone } \\
Injection Treatment
\end{tabular}

The treatment of tennis elbow with local injection of methylprednisolone is the most favoured of all treatments today. It is because easy availability and low cost and well compliance. Most of the reported series show an improvement or cure rate of average $68.57 \%$ and recurrence rate of $51 \%$. Present study is comparable with the previous study reports of $70 \%$ of improvement and $42.86 \%$ of recurrence. ${ }^{9}$

\section{Injection 50\% Dextrose}

\begin{tabular}{|c|c|c|}
\hline Name of the Author & Results (\%) & Recurrence (\%) \\
\hline Hackett GS (1993) & 81.89 & 29.67 \\
\hline Schnirring L (2000) & 76.56 & 21.19 \\
\hline Dagenais S (2006) & 83.27 & 23.14 \\
\hline David Rabago (2013) & 74.93 & 28.1 \\
\hline Present Study (2015) & 80 & 25 \\
\hline \multicolumn{2}{|c|}{ Table 5: Incidence of 50\% Dextrose Treatment } \\
\hline
\end{tabular}

Injection $50 \%$ dextrose is the most commonly used prolotherapy than other injections used in prolotherapy like sodium muriate because of its easy availability and less complications. Only a relative contraindication of this treatment is diabetes mellitus. ${ }^{10,11,12,13}$ Most of the reported series shows an improvement of average of $79.19 \%$ and recurrence rate of average of $24.47 \%$. Present study is comparable with the previous study reports of $80 \%$ improvement and $25 \%$ of recurrence.

\section{Injection Autologous Blood}

\begin{tabular}{|c|c|c|}
\hline Name of the Author & Results (\%) & Recurrence (\%) \\
\hline Edwards SG14 (2003) & 4.76 & 8.26 \\
\hline $\begin{array}{c}\text { Lee TG, Ahmad TS } \\
(2007)\end{array}$ & 88.61 & 13.24 \\
\hline Kutay E (2010) & 87.93 & 10.48 \\
\hline Kazemi M (2010) & 83.87 & 16.12 \\
\hline Wolf JM (2011) & 85.31 & 9.27 \\
\hline Present Study (2015) & 90 & 11.11 \\
\hline \multicolumn{2}{|c|}{ Table 6: Incidence of Autologous Blood Treatment } \\
\hline
\end{tabular}

This method of treatment of tennis elbow is effective and can be given in all patients except who has a haematological diseases like haemophilia, etc.

The effectiveness and recurrence of this treatment and which is comparable with the present study. Most of the reported series shows an improvement of average $86.09 \%$ and recurrence rate of average $11.47 \%$. Present study is comparable with the previous study reports of $90 \%$ improvement and $11.11 \%$ of recurrence. ${ }^{15,16,17}$ 


\section{Injection Platelet Rich Plasma}

\begin{tabular}{|c|c|c|}
\hline Name of the Author & Results (\%) & Recurrence (\%) \\
\hline $\begin{array}{c}\text { Mishra A, Pavelko T } \\
\text { (2006) }\end{array}$ & 93 & - \\
\hline $\begin{array}{c}\text { S Sampson, M. } \\
\text { Gerhadt (2008) }\end{array}$ & 94.12 & 4.63 \\
\hline $\begin{array}{c}\text { Andia I, Sanchaz M } \\
\text { (2010) }\end{array}$ & 90.97 & 1.48 \\
\hline $\begin{array}{c}\text { Del Buono A, Papalia } \\
\text { R (2011) }\end{array}$ & 91.67 & 3.23 \\
\hline Present Study (2015) & 90 & - \\
\hline \multicolumn{2}{|c|}{ Table 7: Incidence of Platelet Rich Plasma Treatment } \\
\hline
\end{tabular}

This treatment in tennis elbow is the most effective and lowest recurrence rate than any of the above treatment discussed, but its limitations are technically demanding.

The effectiveness and recurrence of this treatment and which is comparable with the present study.

Most of the reported series shows an improvement of average $92.44 \%$ and recurrence rate of average 3.13\%. Present study is comparable with the previous study reports of $90 \%$ improvement and nil recurrence. $18,19,20$

- In conclusion, it can be said that Platelet Rich Plasma seems to be the best method of conservative treatment, because its effectiveness were rapid and high with low recurrence rate.

- Autologous Blood has similar effectiveness as Platelet Rich Plasma, but recurrences were noted.

- $50 \%$ Dextrose and Methylprednisolone are of similar effectiveness, but Methylprednisolone were rapid acting and high recurrence than $50 \%$ Dextrose.

- But on the whole, the use of ultrasonic has proved to be disappointing due to its low effectiveness and high recurrence rate.

\section{REFERENCES}

1. Vicenzino B, Wright A. Effects of a novel manipulative physiotherapy technique on tennis elbow: a single case study. Man Ther 1995;1(1):30-5.

2. Verhaar JA. Tennis elbow: anatomical, epidemiological and therapeutic aspects. Int Orthop 1994;18(5):263-7.

3. Walker-Bone KE, Palmer KT, Reading I, et al. Soft-tissue rheumatic disorders of the neck and upper limb: prevalence and risk factors. Semin Arthritis Rheum 2003;33(3):185-203.

4. Shiri R, Viikari-Juntura E, Varonen H, et al. Prevalence and determinants of lateral and medial epicondylitis: a population study. Am J Epidemiol 2006;164(11):1065-74.

5. Bisset L, Paungmali A, Vicenzino B, et al. A systematic review and meta-analysis of clinical trials on physical interventions for lateral epicondylalgia. Br J Sports Med 2005;39:411-22.
6. Garden RS. Tennis elbow. The Journal of bone and joint surgery 1961;43B:100-6.

7. Hohl M. Physical and psychosocial risk factors for lateral epicondylitis: a population based case-referent study. Occup Environ Med 1961:322-9.

8. Haake M, König IR, Decker T, et al. Extracorporeal shock wave therapy in the treatment of lateral epicondylitis: a randomized multicenter trial. J Bone Joint Surg Am 2002;84-A(11):1982-91.

9. Smidt N, Assendelft WJ, van der Windt DA, et al. Corticosteroid injections for lateral epicondylitis: a systematic review. Pain 2002;96(1-2):23-40.

10. Hackett GS, Hemwall GA, Montgomery GA. Ligament and tendon relaxation treated by prolotherapy. $5^{\text {th }}$ ed. Oak Park: Gustav A. Hemwall 1992:96.

11. Schnirring L. Are your patients asking about prolotherapy? Physician Sportsmed 2000;28(8):15-7.

12. Dagenais S, Ogunseitan O, Haldeman S, et al. Side effects and adverse events related to intraligamentous injection of sclerosing solutions (prolotherapy) for back and neck pain: a survey of practitioners. Arch Phys Med Rehabil 2006;87(7):909-13.

13. Rabago D, Lee KS, Ryan M, et al. Hypertonic dextrose and morrhuate sodium injections (prolotherapy) for lateral epicondylosis (tennis elbow). Am J Phys Med Rehabil 2013;92(7):587-96.

14. Edwards SG, Calandruccio JH. Autologous blood injections for refractory lateral epicondylitis. Journal of Hand Surgery 2003;28(2):272-8.

15. Lee TG, Ahmad TS. Intralesional autologous blood injection compared to corticosteroid injection for treatment of chronic plantar fasciitis. A prospective, randomized, controlled trial. Foot Ankle Int 2007;28(9):984-90.

16. Kazemi M, Azma K, Tavana B, et al. Autologous blood versus corticosteroid local injection in the short-term treatment of lateral elbow tendinopathy: a randomized clinical trial of efficacy. Am J Phys Med Rehabil 2010;89(8):660-7.

17. Wolf JM, Ozer K, Scott F, et al. Comparison of autologous blood, corticosteroid and saline injection in the treatment of lateral epicondylitis: a prospective, randomized, controlled multicenter study. J Hand Surg 2011;36(8):1269-72.

18. Mishra A, Pavelko T. Treatment of chronic elbow tendinosis with buffered platelet-rich plasma. Am J Sports Med 2006;34(11):1774-8.

19. Andia I, Sanchez M, Maffulli N. Tendon healing and platelet-rich plasma therapies. Expert Opin Biol Ther 2010;8(10):1415-26.

20. Buono DA, Papalia R, Denaro V, et al. Platelet rich plasma and tendinopathy: state of the art. Int J Immunopathol Pharmacol 2011;24(1 Suppl 2):79-83. 